\title{
Visualization of Candidate Division OP3 Cocci in Limonene-Degrading Methanogenic Cultures
}

\author{
Rotaru, Amelia-Elena ${ }^{1 \dagger}$, Regina Schauer ${ }^{1}$, Christina Probian ${ }^{1}$, Marc Mussmann ${ }^{2}$, and Jens Harder ${ }^{1 *}$ \\ ${ }^{1}$ Department of Microbiology, Max Planck Institute for Marine Microbiology, Celsiusstrasse 1, D-28359, Bremen, Germany \\ ${ }^{2}$ Department of Microbial Ecology, Max Planck Institute for Marine Microbiology, Celsiusstrasse 1, D-28359, Bremen, Germany
}

Received: October 17, 2011 / Revised: December 4, 2011 / Accepted: December 5, 2011

\begin{abstract}
Members of candidate division OP3 were detected in $16 \mathrm{~S}$ rRNA gene clone libraries from methanogenic enrichment cultures that utilized limonene as a carbon and energy source. We developed probes for the visualization of OP3 cells. In situ hybridization experiments with newly designed OP3-specific probes [OP3-565 and Eub-338(VI)] revealed abundant small OP3 cocci attached to larger cells. Syntrophic Deltaproteobacteria, OP3 cells, and methanogens affiliating with Methanoculleus and Methanosaeta formed the limonenedegrading community.
\end{abstract}

Keywords: Candidate division OP3, monoterpene, limonene, hydrocarbon degradation, methanogenesis, syntrophy

The bacterial candidate division OP3 was first discovered in 16S rRNA gene libraries generated from sediment of the Obsidian Pool, a hot spring in the Yellowstone National Park [11]. Phylogenetic analysis placed this lineage together with anaerobic ammonium oxidizers (anammox bacteria) and Planctomycetales [22, 31]. Candidate division OP3 is ubiquitous in anoxic environments, such as wastewater treatment plants, and was recently found in methanogenic reactors [1, 4, 26, 29]. Metagenomic studies of OP3 identified the catalytic subunit of the anaerobic carbon monoxide dehydrogenase/acetyl-CoA synthase, the obligate anaerobic key enzyme of the Wood-Ljungdahl pathway [6]. The metabolism of OP3 is yet unknown and cultivation of members of this candidate division will assist in revealing their physiology and function in syntrophic communities. In this note, we report the observation of OP3 cells by catalyzed reporter deposition-fluorescence in situ hybridization experiments (CARD-FISH) in methanogenic enrichment

\footnotetext{
* Corresponding author

Phone: +49-(0)-421-2028750; Fax: +49-(0)-421 2028790;

E-mail: jharder@mpi-bremen.de
}

Tresent address: Amelia-Elena Rotaru, Department of Microbiology, University of Massachusetts, Amherst, 639-North Pleasant Street, Amherst, MA-01003-9298, USA cultures initiated on monoterpenes [7]. Limonene, the monoterpene substrate used in this study, is produced by the plastids of plants $[12,15]$ and is, alongside toluene, a major indoor volatile organic compound. Sediment-free enrichments were transferred once a year with $2-5 \%$ limonene in $30 \mathrm{ml}$ of 2,2,4,6,8,8-heptamethylnonane (HMN), in $300 \mathrm{ml}$ of methanogenic medium [7]. Cultures produced methane for up to two years (Fig. 1). Limonene consumption and methane formation were demonstrated by headspace gas chromatography on a Shimadzu 14B gas chromatograph with flame ionization detector and an isothermal separation
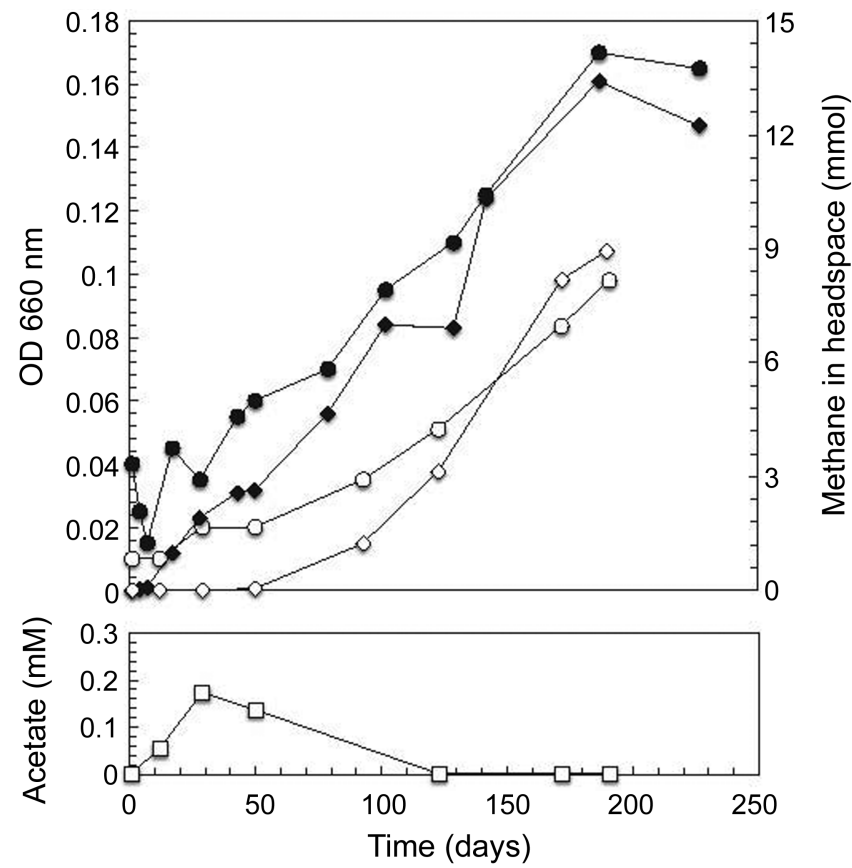

Fig. 1. Methane production (diamonds) and growth (circles) of limonene-utilizing enrichment cultures in the presence or absence of acetate ( $2 \mathrm{mM}$, filled and open symbols, respectively).

Lower panel: transient acetate formation in the culture without $2 \mathrm{mM}$ acetate coincidenced with a longer lag phase of the culture. Observations represent average values of two replicates. 
at $200^{\circ} \mathrm{C}$ and $110^{\circ} \mathrm{C}$, respectively. Over 250 days of incubation, cell-free controls did not show limonene loss. After 250 days of incubation, analyses of limonene consumption and methane production revealed a recovery of nearly $60 \%$ of the carbon from limonene as methane gas. This suggested the stoichiometry: $\mathrm{C}_{10} \mathrm{H}_{16}+6 \mathrm{H}_{2} \mathrm{O} \rightarrow$
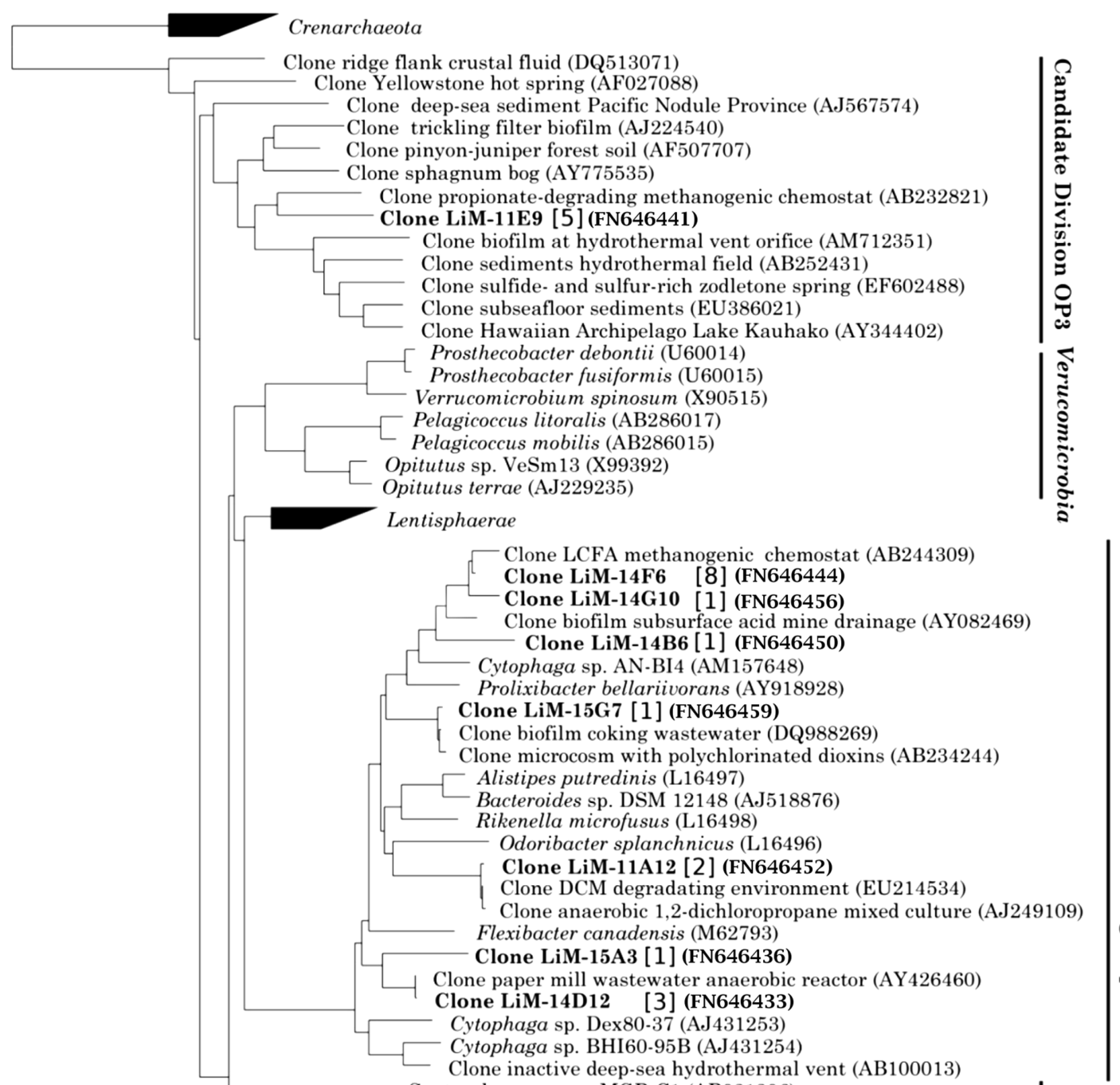

Clone inactive deep-sea hydrothermal vent (AB100013)

Syntrophomonas sp. MGB-C1 (AB021306)

Clone LiM-15G5 [1] (FN646462)

Syntrophomonas cellicola (DQ288691)

Syntrophomonas wolfei subsp. saponavida (DQ666176)

Syntrophomonas palmitatica (AB274039)

Clone organic waste degrading packed-bed reactor (AB274497)

Desulfovibrionales

Desulfuromonadales

Syntrophobacter fumaroxidans (X82874)

Syntrophobacter pfennigii (X82875)

Clone acidophilic methanogenic enrichment sphagnum peat bog (AF524857)

Syntrophobacter wolinii (X70905)

Clone LiM-14A12 [11] (FN646454)

Syntrophobacter sp. (AJ237605)

Clone LiM-13G9 [1] (FN646458)

- Clone LCFA methanogenic enrichment cultures (DQ984663)

Clone LCFA methanogenic enrichment cultures (DQ459216)

Fig. 2. Maximum parsimony tree of Bacteria 16S rRNA gene sequences.

Crenarchaeota were used as the outgroup. The phylotypes obtained in this study are emphasized in bold, and in parenthesis is the number of full 16S rRNA gene sequences with identity above $98.5 \%$. Related sequences of representative microorganisms can be accessed at the NCBI using the tags given in parenthesis. The scale bar represents 10 substitutions per 100 nucleotides. 
$7 \mathrm{CH}_{4}+3 \mathrm{CO}_{2}\left(\Delta \mathrm{G}_{0}{ }^{\prime}=-348 \mathrm{~kJ} \mathrm{~mol}^{-1}\right.$ limonene $)$. Transient formation of fatty acids in the medium (Fig. 1) was observed by HPLC [25]. Acetate was routinely added in small amounts in the medium $(2 \mathrm{mM})$. It facilitated maintainance of the methanogenic community after transfer. In the absence of acetate, solely with limonene, a longer lag phase of 3 months was observed before methane production started (Fig. 1). These cultures transiently produced acetate, up to $0.2 \mathrm{mM}$ (Fig. 1). Thus, acetate is involved as an intermediate in the syntrophic limonene degradation, likely being synthesized by syntrophic Bacteria and consumed by acetoclastic, methanogenic Archaea.

We selected the 16S rRNA gene approach to identify the community diversity and CARD-FISH studies to reveal the community structure. Genomic DNA of a $5 \mathrm{ml}$ cell culture was extracted with the Qiagen genomic tip 100/G according to the manufacturer's instruction (Qiagen, Hilden, Germany). A $25 \mathrm{ng}$ amount of high-molecular weight DNA was used to amplify the $16 \mathrm{~S}$ rRNA gene with bacterial primers $8 \mathrm{~F}$ and $1492 \mathrm{R}[9,14]$ and archaeal primer pairs 21F-958R and 21F-1492R [5,28]. The reaction mix consisted of $2 \mu \mathrm{M}$ of each primer, $0.2 \mathrm{mM}$ dNTPs, $0.04 \mathrm{U}$ Taq polymerase, and $1 \times$ PCR buffer in $50 \mu$ l. After an initial denaturing step of $4 \mathrm{~min}$ at $94^{\circ} \mathrm{C}$, polymerase was added at $80^{\circ} \mathrm{C}$. The 32 cycles involved a denaturing step for $1 \mathrm{~min}$ at $94^{\circ} \mathrm{C}, 1 \mathrm{~min}$ primer annealing at $42^{\circ} \mathrm{C}$ for Bacteria and $58^{\circ} \mathrm{C}$ for Archaea, and $3 \mathrm{~min}$ elongation at $72^{\circ} \mathrm{C}$. The A-overhang for cloning was introduced by a final elongation at $60^{\circ} \mathrm{C}$ for $60 \mathrm{~min}$. The bacterial and archaeal amplicons were purified and cloned into the pGEM-T Easy vector (Promega, Madison, WI, USA) and the pCR4-TOPO vector (Invitrogen, Grand Island, NY, USA), respectively. The recombinant plasmids were introduced into E. coli DH5 $\alpha$ (Promega, Madison, WI, USA) and E. coli TOP10 (Invitrogen, Grand Island, NY, USA)-, respectively. Amplified rDNA restriction analysis (ARDRA) with the restriction endonucleases $B s u$ RI and $R s a \mathrm{I}$ on 327 Bacteria clones and 141 Archaea clones and partial sequencing of 100 randomly selected clones directed the full sequence analyses of representative 16S rRNA genes (accession numbers FN646432 to FN646495). Maximum parsimony phylogenetic trees were calculated excluding the influence of highly variable positions in ARB [18, 23]. $16 \mathrm{~S}$ rRNA gene sequences with more than $98.5 \%$ identity were regarded as one operational taxonomic unit (OTU) [27]. Phylogenetic affiliations of the 35 representative 16S Bacteria sequences and 28 representative $16 \mathrm{~S}$ Archaea sequences are shown in Fig. 2 and 3, respectively.

The characterization of the community structure required the design of novel probes targeting OP3 sequences, Eub338(VI) (5'-GCAGCCTCCCGTAGGAGT-3') and OP3-565 (5'-TACCTGCCCTTTACACCC-3'). Probes were developed in silico with the software ARB [http://www.arb-home.de, $18,23]$. OP3-565 had 1.2 weighted mismatches to

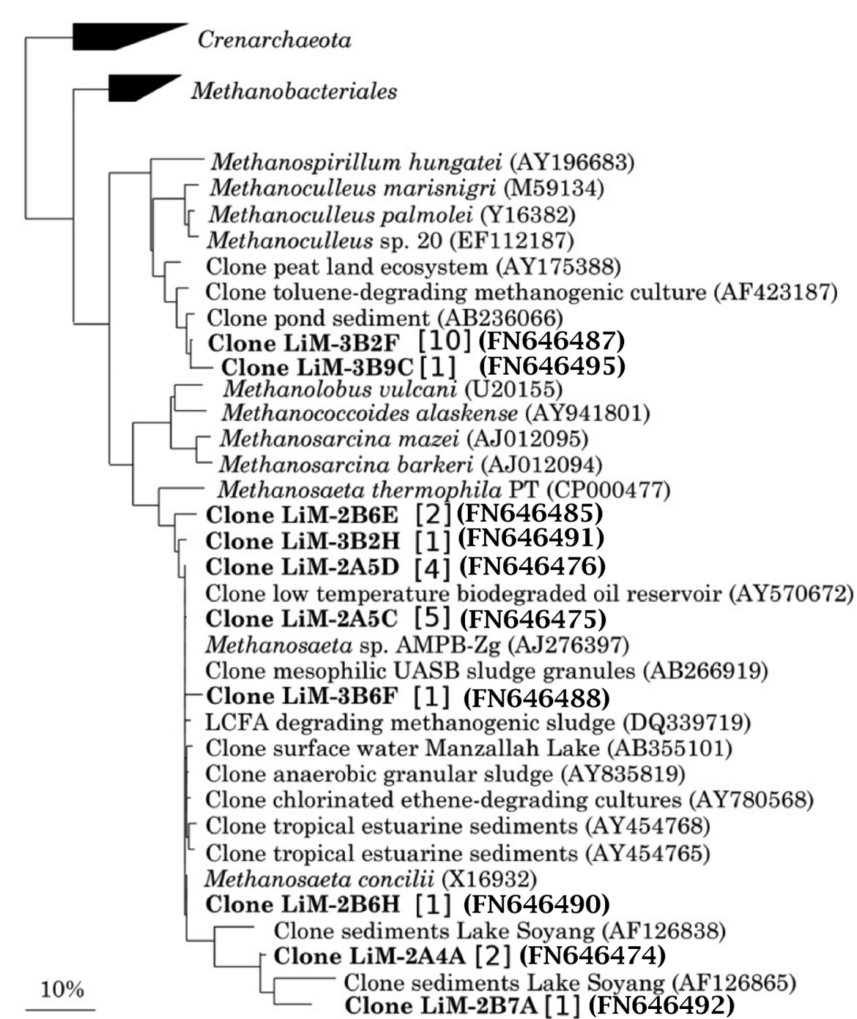

Fig. 3. Maximum parsimony tree of Archaea 16S rRNA gene sequences.

Crenarchaeota were used as the outgroup. The phylotypes obtained in this study are emphasized in bold, and in parenthesis is the number of full $16 \mathrm{~S}$ rRNA gene sequences with identity above $98.5 \%$. Related sequences of representative microorganisms can be accessed at the NCBI using the tags given in parenthesis. The scale bar represents 10 substitutions per 100 nucleotides.

Thialkalivibrio halophylus (DSM 15791) and Marinitoga piezophila (DSM 14283), which served as the control for hybridization experiments with horseradish peroxidase (HRP) 5'-modified probes [21]. Newly designed and previously tested probes [17] were applied: Eub-338(I) [2] in equimolar mix with probe Eub-338(VI) designed in this study, Arch-915 [28], CF-319a [19], Delta-495a in equimolar mix with its competitor [16], and the newly designed OP3565. As the control, we used the nonsense probe Non-338, which gave one signal for 300 DAPI-stained cells.

Microscopic observations showed the presence of numerous morphotypes in the enrichment, from small cocci and vibrios to long filaments (Fig. 4a). Bacteria represented $40 \%$ of the microbial community, whereas Archaea represented $33 \%$, as detected by CARD-FISH with phylaspecific probes (Eub338 I+VI, Arch915). The general Archaea probe Arch-915 targeted Methanosaeta-like filaments and numerous rod-shaped cells. Archaea 16S rRNA gene sequences were related to Methanosaeta $(>99 \%$ identity) and far related to Methanoculleus palmollei (91.6\% identity) and Methanospirillum hungatei 


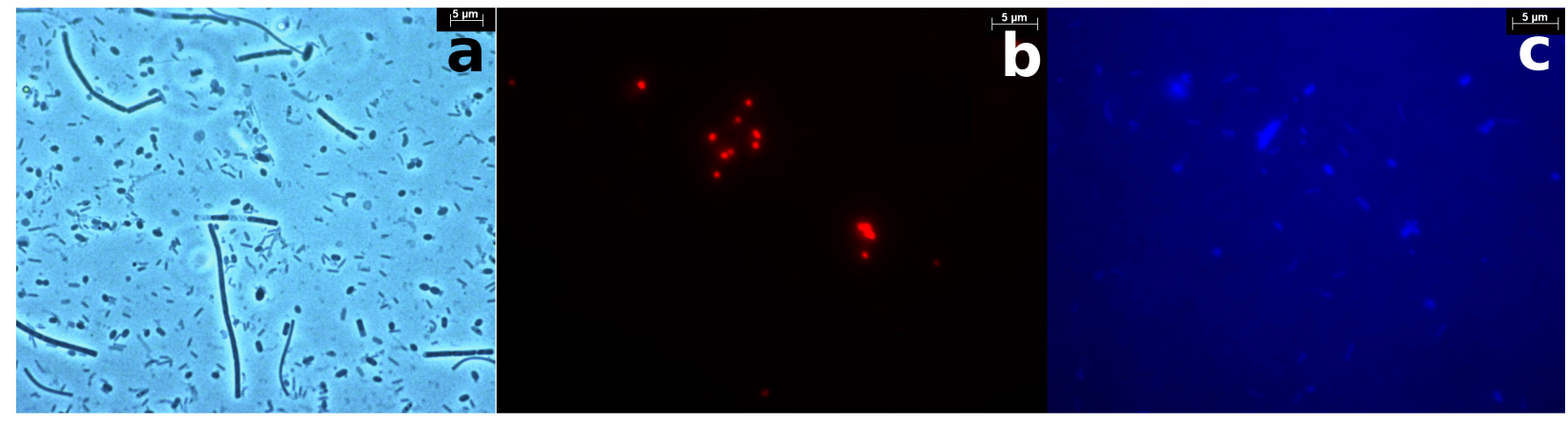

Fig. 4. Microscopic images of samples from methanogenic enrichment cultures thriving on limonene, as visualized by (a) phase contrast microscopy and (b) epifluorescence microscopy with a newly designed OP3-specific probe, OP3-565, and (c) the same microscopic field visualized by a general DNA dye, DAPI.

(Fig. 3). Methanosaeta are slowly growing acetoclastic methanogens with high affinity to acetate [13]. The genera Methanospirillum and Methanoculleus represent hydrogenand formate-utilizing methanogens [32]. This suggests that acetate as well as formate and hydrogen are involved in the electron transfer from limonene-degrading microorganisms to methanogens.

Most of the bacterial clones retrieved from the enrichment cultures showed low 16S similarity with cultured microorganisms of the following Bacteria lineages: candidate division OP3, Deltaproteobacteria, Bacteroidetes, and Firmicutes (Fig. 2). The first three groups were dominant in the clone library. However, specific probes for Deltaproteobacteria (Delta-495a) and OP3 (OP3-565) accounted collectively for almost the entire bacterial population (30\% of all cells), whereas Bacteroidetes accounted for less than $1 \%$ of all DAPI-stained cells.

Bacteroidetes were related to Prolixibacter bellariivorans ( $81 \%$ to $89 \%$ identity) and Alistipes putredinis (84.1\%). Genus Prolixibacter is represented by facultative anaerobes [10], whereas genus Alistipes includes strictly anaerobic microorganisms [24]. The low numbers of Bacteroidetes suggests no or a minor function for these cells in the syntrophic degradation of limonene.

Firmicutes were represented by only one phylotype with $91.2 \%$ identity to Syntrophomonas sp. and only $95 \%$ to the closest uncultured relative, a sequence retrieved from a reactor degrading organic waste. Syntrophomonas and Syntrophobacter are the ideal candidates for syntrophic transformation of fatty acids and alcohols into acetate, hydrogen, and carbon dioxide [20]. The Deltaproteobacteria curved rods were found abundant $(12 \%)$ in limonenedegrading enrichments during mid-exponential growth, as identified by CARD-FISH with a specific probe (Delta495a). Deltaproteobacteria phylotypes were related to Syntrophobacter (Fig. 2), having as closest relative (90-96\% identity) Syntrophobacter fumaroxidans strain MBOP [8].

The abundance of candidate division OP3 cells attached to rod-shaped microorgansisms indicates a more complex degradation pathway. They made up for $18 \%$ of all cells in the limonene-consuming methanogenic community, as determined by a specific designed probe (OP3-565). Cells of candidate division OP3 were small and round-shaped (Fig. 4b), and they were free-living or found attached to larger cells of distinct phylogeny (Fig. $4 \mathrm{~b}$ and $4 \mathrm{c}$ ). The abundance of candidate division OP3 members during exponential growth on limonene suggests an important role in the degradation of this monoterpene. Because syntrophic cultures are often limited by the flux of electron-transferring molecules between the partners, we consider based on the attachment to larger cells that candidate division OP3 cells could actually contribute to the pool of electron-transferring intermediates in limonene syntrophic degradation. One possibility is the production of formate, described as a superior alternative to hydrogen as a transfer intermediate under mesophilic conditions $[3,30]$.

\section{Acknowledgments}

We thank the Max Plank Society and the International Max Planck Research School for Marine Microbiology for financial support.

\section{REFERENCES}

1. Alfreider, A., C. Vogt, and W. Babel. 2002. Microbial diversity in an in situ reactor system treating monochlorobenzene contaminated groundwater as revealed by $16 \mathrm{~S}$ ribosomal DNA analysis. Syst. Appl. Microbiol. 25: 232-240.

2. Amann, R. I., B. J. Binder, R. J. Olson, S. W. Chisholm, R. Devereux, and D. A. Stahl. 1990. Combination of 16S rRNAtargeted oligonucleotide probes with flow cytometry for analyzing mixed microbial populations. Appl. Environ. Microbiol. 56: 1919-1925.

3. Boone, D. R., R. L. Johnson, and Y. Liu. 1989. Diffusion of the interspecies electron carriers $\mathrm{H}(2)$ and formate in methanogenic ecosystems and its implications in the measurement of $\mathrm{K}(\mathrm{m})$ for 
H(2) or formate uptake. Appl. Environ. Microbiol. 55: 17351741.

4. Chouari, R., D. Le Paslier, P. Daegelen, P. Ginestet, J. Weissenbach, and A. Sghir. 2003. Molecular evidence for novel Planctomycete diversity in a municipal wastewater treatment plant. Appl. Environ. Microbiol. 69: 7354-7363.

5. DeLong, E. F. 1992. Archaea in coastal marine environments. Proc. Natl. Acad. Sci. USA 89: 5685-5689.

6. Glöckner, J., M. Kube, P. M. Shrestha, M. Weber, F. O. Glöckner, R. Reinhardt, and W. Liesack. 2010. Phylogenetic diversity and metagenomics of candidate division OP3. Environ. Microbiol. 12: 1218-1229.

7. Harder, J. and S. Foss. 1999. Anaerobic formation of the aromatic hydrocarbon $p$-cymene from monoterpenes by methanogenic enrichment cultures. Geomicrobiol. J. 16: 295-305.

8. Harmsen, H. J., B. L. Van Kuijk, C. M. Plugge, A. D. Akkermans, W. M. De Vos, and A. J. Stams. 1998. Syntrophobacter fumaroxidans sp. nov., a syntrophic propionate-degrading sulfatereducing bacterium. Int. J. Syst. Bacteriol. 48: 1383-1387.

9. Hicks, R. E., R. I. Amann, and D. A. Stahl. 1992. Dual staining of natural bacterioplankton with 4',6-diamidino-2-phenylindole and fluorescent oligonucleotide probes targeting kingdom-level 16S ribosomal-RNA sequences. Appl. Environ. Microbiol. 58: 2158-2163.

10. Holmes, D. E., K. P. Nevin, T. L. Woodard, A. D. Peacock, and D. R. Lovley. 2007. Prolixibacter bellariivorans gen. nov., sp. nov., a sugar-fermenting, psychrotolerant anaerobe of the phylum Bacteroidetes, isolated from a marine-sediment fuel cell. Int. J. Syst. Evol. Microbiol. 57: 701-707.

11. Hugenholtz, P., C. Pitulle, K. L. Hershberger, and N. R. Pace. 1998. Novel division level bacterial diversity in a Yellowstone hot spring. J. Bacteriol. 180: 366-376.

12. Hyatt, D. C., B. Youn, Y. Zhao, B. Santhamma, R. M. Coates, R. B. Croteau, and C. Kang. 2007. Structure of limonene synthase, a simple model for terpenoid cyclase catalysis. Proc. Natl. Acad. Sci. USA 104: 5360-5365.

13. Jetten, M. S. M., A. J. M. Stams, and A. J. B. Zehnder. 1990. Acetate threshold values and acetate activating enzymes in methanogenic bacteria. FEMS Microbiol. Lett. 73: 339-344.

14. Kane, M. D., L. K. Poulsen, and D. A. Stahl. 1993. Monitoring the enrichment and isolation of sulfate-reducing bacteria by using oligonucleotide hybridization probes designed from environmentally derived 16S ribosomal-RNA sequences. Appl. Environ. Microbiol. 59: 682-686.

15. Kreuzwieser, J., J. P. Schnitzler, and R. Steinbrecher. 1999. Biosynthesis of organic compounds emitted by plants. Plant Biol. 1: 149-159.

16. Loy, A., A. Lehner, N. Lee, J. Adamczyk, H. Meier, J. Ernst, et al. 2002. Oligonucleotide microarray for $16 \mathrm{~S}$ rRNA gene-based detection of all recognized lineages of sulfate-reducing prokaryotes in the environment. Appl. Environ. Microbiol. 68: 5064-5081.

17. Loy, A., F. Maixner, M. Wagner, and M. Horn. 2007. ProbeBase - an online resource for rRNA-targeted oligonucleotide probes: New features 2007. Nucleic Acid Res. 35: D800-D804.

18. Ludwig, W., O. Strunk, R. Westram, L. Richter, H. Meier, Yadhukumar, et al. 2004. ARB: A software environment for sequence data. Nucleic Acid Res. 32: 1363-1371.

19. Manz, W., R. Amann, W. Ludwig, M. Vancanneyt, and K. H. Schleifer. 1996. Application of a suite of 16S rRNA-specific oligonucleotide probes designed to investigate bacteria of the phylum Cytophaga-Flavobacter-Bacteroides in the natural environment. Microbiology 142: 1097-1106.

20. McInerney, M. J., C. G. Struchtemeyer, J. Sieber, H. Mouttaki, A. J. Stams, B. Schink, et al. 2008. Physiology, ecology, phylogeny, and genomics of microorganisms capable of syntrophic metabolism. Ann. N.Y. Acad. Sci. 1125: 58-72.

21. Pernthaler, A., J. Pernthaler, and R. Amann. 2002. Fluorescence in situ hybridization and catalyzed reporter deposition for the identification of marine bacteria. Appl. Environ. Microbiol. 68: 3094-3101.

22. Pilhofer, M., K. Rappl, C. Eckl, A. P. Bauer, W. Ludwig, K. H. Schleifer, and G. Petroni. 2008. Characterization and evolution of cell division and cell wall synthesis genes in the bacterial phyla Verrucomicrobia, Lentisphaerae, Chlamydiae, and Planctomycetes and phylogenetic comparison with rRNA genes. J. Bacteriol. 190: 3192-3202.

23. Pruesse, E., C. Quast, K. Knittel, B. M. Fuchs, W. Ludwig, J. Peplies, and F. O. Glockner. 2007. SILVA: A comprehensive online resource for quality checked and aligned ribosomal RNA sequence data compatible with ARB. Nucleic Acids Res. 35: 7188-7196.

24. Rautio, M., E. Eerola, M. L. Vaisanen-Tunkelrott, D. Molitoris, P. Lawson, M. D. Collins, and H. Jousimies-Somer. 2003. Reclassification of Bacteroides putredinis (Weinberg et al., 1937) in a new genus Alistipes gen. nov., as Alistipes putredinis comb. nov., and description of Alistipes finegoldii sp. nov., from human sources. Syst. Appl. Microbiol. 26: 182-188.

25. Rotaru, A. E., C. Probian, H. Wilkes, and J. Harder. 2010. Highly enriched Betaproteobacteria growing anaerobically with p-xylene and nitrate. FEMS Microbiol. Ecol. 71: 460-468.

26. Shigematsu, T., S. Era, Y. Mizuno, K. Ninomiya, Y. Kamegawa, S. Morimura, and K. Kida. 2006. Microbial community of a mesophilic propionate-degrading methanogenic consortium in chemostat cultivation analyzed based on 16S rRNA and acetate kinase genes. Appl. Microbiol. Biotechnol. 72: 401-415.

27. Stackebrandt, E. and J. Ebers. 2006. Taxonomic parameters revisited: Tarnished gold standards. Microbiol. Today 33: 153-156.

28. Stahl, D. A. and R. Amann. 1991. Development and application of nucleic acid probes. In E. Stackebrandt and M. Goodfellow (eds.). Nucleic Acid Techniques in Bacterial Systematic. John Wiley \& Sons Ltd, Chichester, England.

29. Tang, Y. Q., T. Shigematsu, S. Morimura, and K. Kida. 2007. Effect of dilution rate on the microbial structure of a mesophilic butyrate-degrading methanogenic community during continuous cultivation. Appl. Microbiol. Biotechnol. 75: 451-465.

30. Thiele, J. H. and J. G. Zeikus. 1988. Control of interspecies electron flow during anaerobic digestion: Significance of formate transfer versus hydrogen transfer during syntrophic methanogenesis in flocs. Appl. Environ. Microbiol. 54: 20-29.

31. Wagner, M. and M. Horn. 2006. The Planctomycetes, Verrucomicrobia, Chlamydiae and sister phyla comprise a superphylum with biotechnological and medical relevance. Curr. Opin. Biotechnol. 17: 241-249.

32. Zellner, G., P. Messner, J. Winter, and E. Stackebrandt. 1998. Methanoculleus palmolei sp. nov., an irregularly coccoid methanogen from an anaerobic digester treating wastewater of a palm oil plant in North-Sumatra, Indonesia. Int. J. Syst. Bacteriol. 48: 1111-1117. 